\title{
The Machinability and Wear Mechanism of TiN Coated Tools in Dry Turning of AISI 4119
}

\author{
Wenqiang $\operatorname{Han}^{\text {a }}$, Sitao Chen \\ AVIC Chengdu Aircraft Industrial (Group) Co., Ltd, Chengdu 610073, China \\ anhwhfl@hotmail.com
}

Keywords: TiN coated tools, dry turning, cutting forces, tool wear.

\begin{abstract}
To examine the tribological properties of TiN films and the cutting performance of TiN coated carbide tools, TiN coatings were deposited by using direct current-pulse bias voltage Arc Ion Deposition technique on AISI 1045 steel and YG6 indexable turning tool. The dry tribological behaviors of TiN coating on AISI 1045 steel have been studied in a ball-on-disk tribometer. The dry turning tests of AISI 4119 steel were performed using TiN coated and uncoated carbide tools on the CA6140A lathe. The effects of the two kinds of tools on cutting forces, surface qualities and tool wear have been investigated to assess the performance of TiN coated cemented carbide tools. The results showed that TiN films produce lower friction coefficient than AISI 1045 steel; The main wear mechanisms of TiN coated tool is abrasive wear and accompanied with adhesive, diffusion and oxidation wear.
\end{abstract}

\section{Introduction}

Dry turning technology has been developed rapidly since the 1990s. Without using cutting fluids, no pollution to the environment and less the machining cost, dry turning is becoming the main processing method at the present [1].

The cutting performance, life and wear mechanism of tools must be taken into account when dry turning steels. In dry machining, there will be much friction and adhesion between the tool and workpiece since they will be subjected to higher temperature. At the same time, it will also dissipate more power and make the tool wear aggravated [2]. As the result, the conventional cutting tools material and the design process is no longer suitable for dry turning. It is becoming a research topic to select proper tool material and design tool surface characteristics. One of the main methods is a layer or multilayer films such as TiN, TiCN, (Al,Ti)N, are deposited on the surface of inserts to enhance the stiffiness and wear resistance of the tools [3].

Compared to the uncoated tools, the performances of coated tools have been enhanced greatly. For example, as the earlier material used in tool protective coating, TiN coatings have excellent wear resistance. It can improve the turning tools performance significantly and enhance the machining precision and efficiency [4]. So, TiN is the perfect tool coating material of low cutting speed. Nowadays, $80 \%$ of all machining operations are performed with coated carbide cutting tools reported by Grzesik.

As the low carbon alloy steel, AISI 4119 steel with excellent comprehensive mechanical properties through carburizing and quenching processing is widely used as mechanical parts in industry and is mainly used for making various mechanical important parts such as gears, connecting rod and gear shaft, etc.

According to the theory of metal-cutting, increasing in cutting speeds can improve surface finished while reducing the cutting forces [5]. The drawback behind the use of high cutting speeds can make the cutting temperature excursion,which is the adverse effect on tool life [6, 7]. For example, titanium alloys or Inconel can be machined using cutting speeds around $250 \mathrm{~m} / \mathrm{min}$ and austenitic stainless steels is performed with cutting speeds between 150 and $350 \mathrm{~m} / \mathrm{min}$ [8]. However, there are few reports on the machining of AISI 4119 steel, especially on the dry turning characteristics of coated tools in the cutting of AISI 4119 steel [9]. Therefore, AISI 4119 steel is used 
as the workpiece material for investigating the machining performance of coated tools in the present study. In this paper, the dry turning tests of AISI 4119 steel were performed in various speeds using TiN coated and uncoated carbide tools on the CA6140A lathe. The cutting forces were detected by SDC-L3M piezoelectric dynamometer. The surface finished quality and the wear value of coated and uncoated carbide tools were compared to assess the performance of TiN coated cemented carbide tools. The wear mechanism of TiN coated tool was investigated though the friction and wear experiments.

\section{Experimental Details}

\section{Machining Tests.}

The workpiece material was AISI 4119 steel with a hardness of 30 HRC in the form of a round bar, and part specimens were bars of $450 \mathrm{~mm}$ length and $46 \mathrm{~mm}$ diameter. The chemical composition (wt. \%) of the workpiece was C 0.21, Si 0.27, Mn 0.55, P 0.035, S 0.035, Cr 0.45, Ni 0.03 and Fe balance and the heat processing was normalizing.

Direct current-pulse bias voltage Arc Ion Deposition (DCBVAID) technique was used for the deposition of TiN coatings on YG6 (6\% of Co) cemented carbide substrates, because the AID technique characterised by a very high ionisation and current density can enable good adhesion between the coatings and the substrates compared to other methods. The following angles were obtained: rake angle $\gamma_{0}=15^{\circ}$, relief angle $\alpha_{0}=8^{\circ}$, inclination angle $\lambda \mathrm{s}=-4^{\circ}$ and side cutting-edge angle $\kappa_{\mathrm{r}}=75^{\circ}$.

The subsystem for measuring the cutting forces was composed of a triaxial SDC-L3M piezoelectric dynamometer, a DJ-CL-1 charge amplifier, a DapBoard/2000 PCI data acquisition board and computer data acquisition software (DasyLab). Fig.1 shows the diagram of cutting dynamometer experiential hardware.

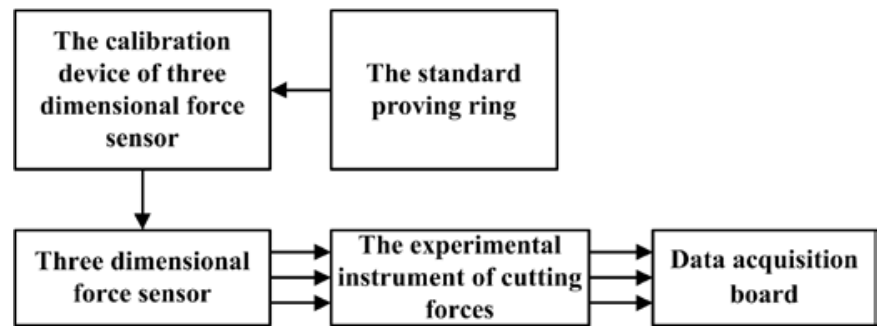

Fig. 1 Diagram of cutting dynamometer experiential hardware

\section{Machining Conditions}

It is generally agreed that the cutting speed is the most dominant factor influencing the tool life, followed by the feed rate and depth of cut. Hence, the cutting force and surface roughness tests were carried out at various cutting speeds (v) between 25 and $172 \mathrm{~m} / \mathrm{min}$, depending on the constant feed rate and depth of cut.

\section{Results and Discussion}

\section{The Friction Properties of TiN Films.}

These specimens were made of AISI 1045 steel as the substrate materials that have been shaped in a form of disc with a diameter of 30mm and thickness of 3mm. TiN films were deposited using DCBVAID technique with the thickness of $3.0 \mu \mathrm{m}$. The tribological behaviors of TiN films have been studied on a ball-on-disk tribometer which produced by Switzerland in air with the temperature of 25 degrees Celsius. The normal load is $1 \mathrm{~N}$ and the sliding speed is $0.08 \mathrm{~m} / \mathrm{s}$ for $100 \mathrm{~m}$.

Fig. 2 shows the friction coefficient of TiN coating and substrate with the sliding distance. At the beginning, the friction coefficient has a low value. The second stage, it gradually increases to a peak about 0.225 . The third stage, it is to reduce to the wave trough, about 0.21 . At the last, it gradually increases to a stable stage, which is about 0.25 . This can be explained as the follows. In the early of sliding, TiN coatings surface have some adsorbates such as oil, dirt and other impurities which can 
form a layer of organic thin film. So the friction coefficient is low. As the sliding continued, the organic substances are gradually eliminated because of actual contact area increasing. At the same time, abrasive particle and furrow were produced on the films. As the result,the friction coefficient is rapidly increased to peak. When abrasive particle increased to a certain degree, third body is formed and the contact area between ball and films is reduced. So friction coefficient is down. Finally, as the abrasive particles produced on the TiN films and left of that reached to a dynamic balance, the friction coefficient is gradually stable.

The average friction coefficient of TiN coatings is 0.25 while the substrate is 0.29 . This indicates that the composite coatings have a better lubricating property than substrate at the same condition. When the sliding distance is over $60 \mathrm{~m}$, friction coefficient of substrate shows a large fluctuation, but TiN films continue to maintain stability.

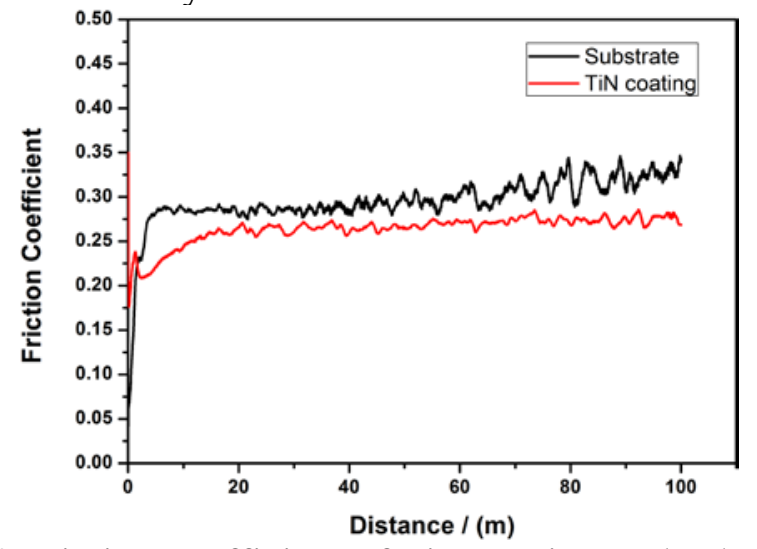

\section{Cutting Forces.}

Fig.2 Friction coefficient of TiN coating and substrate

Fig. 3 illustrates the evolution of the tangential force $\left(F_{c}\right)$, feed force $\left(F_{f}\right)$, and radial force $\left(F_{s p}\right)$ as a function of cutting speeds with coated and uncoated tools in dry turning of AISI 4119 steel. From this figure, it is found that the cutting forces are clearly reduced with the TiN coated tool compared with the uncoated tool. Particularly, in relatively high speed conditions, the cutting forces of the coated tool are much lower than those of the uncoated tool. The advantage in cutting forces is not very obvious in relatively low speed conditions. High speed causes an important increment in the heat of the deformation areas. Due to the low thermal conductivity of the TiN coatings $(0.83 \sim 0.030$ $\mathrm{cal} /\left(\mathrm{cm}\right.$. sec. $\left.^{\circ} \mathrm{C}\right)$ at $\left.27^{\circ} \mathrm{C}\right)$, the heat generated in the machining is taken away from deformation areas quickly by chips. This phenomenon prevents the temperature of TiN coated tools and workpiece increasing rapidly. The adhesion and chemical wear of coated insert are relieved. As the result, the main cutting force is reduced quickly.

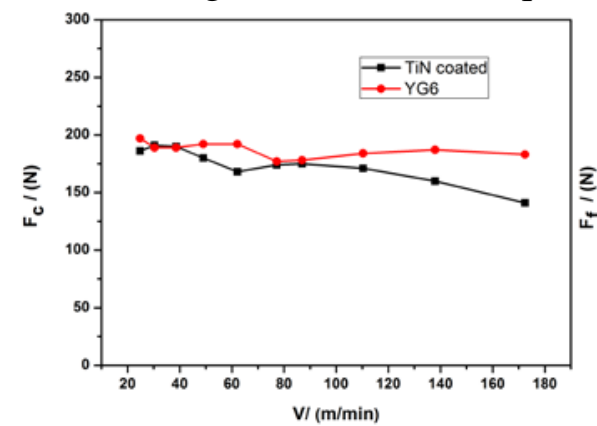

(a)

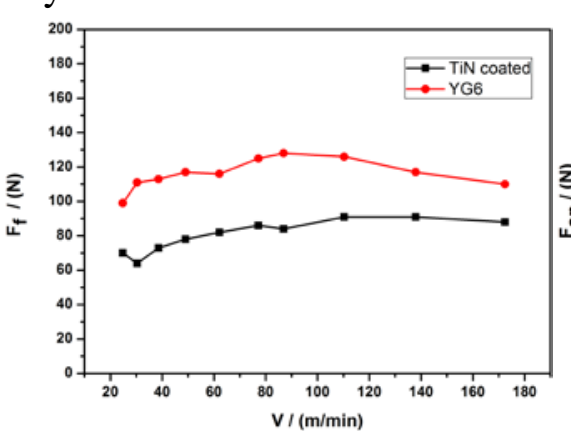

(b)

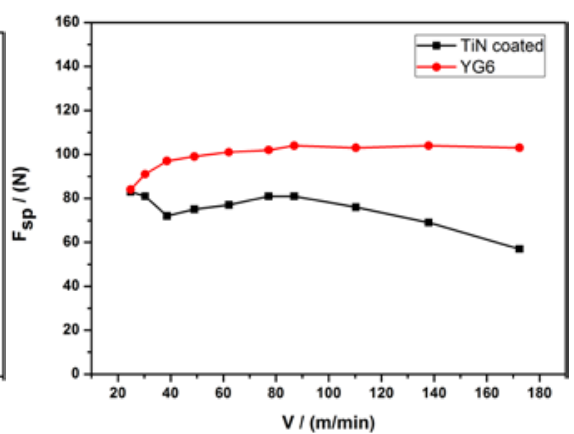

(c)

Fig. 3 Evolution of cutting forces with cutting speed

\section{Analysis of Machined Surface.}

The workpiece surface qualities are poor in the low speeds (as seen in Fig.4). For uncoated tool, the workpiece surface of diagram (a) began to smooth gradually when cutting speed is $62.1 \mathrm{~m} / \mathrm{min}$ and some black chip sticking small particles were found in the cutting speed of $172.4 \mathrm{~m} / \mathrm{min}$. The friction heat produced on the contact surface between the workpiece and tool was increased with the augment of cutting speed. Chip bonding was found on the cutting edge. At the same time, the thermal stress and chemical wear appeared on the contact surface also exercised a great influence on the stability of 
the processing surface quality. For TiN coated tool, the workpiece surface of diagram (b) is becoming smooth gradually in the cutting speed of $49 \mathrm{~m} / \mathrm{min}$ and the black chip sticking small particles were not found during the turning process. The thermal conductivity of the TiN coatings is low. So the heat generated in the machining is taken away from deformation areas quickly by chips. This phenomenon reduced the influence of cutting speed on the surface quality.

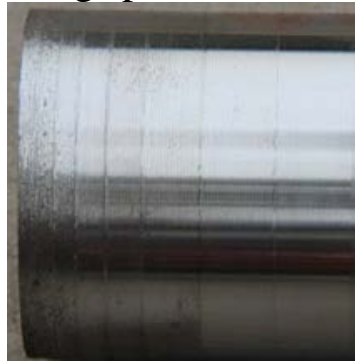

(a)

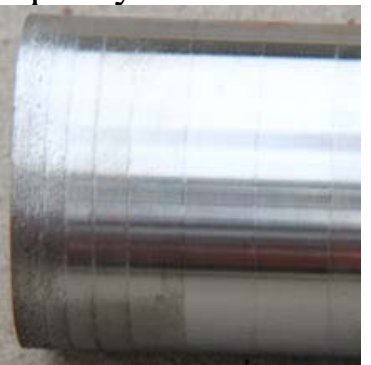

(b)

Fig. 4 Comparing of workpieces surface quality: (a) uncoated; (b) TiN coated

\section{The Wear Mechanisms of Rank Surface of TiN Coated Tool.}

Figure 5 shows the SEM micrograph of the worn rake face of the TiN coated carbide tool at the 32 min. The tool surface scratches are serious. The obvious grinding crack and abrasive wear can be found on the rank surface, especially near the tool nose, where own the highest temperature. Wear mechanisms of this area included abrasion, chemical and diffusion wear [10]. Away from the tool nose the more flat and wider scratch which is no visible adhesive appears. There are residual TiN coatings on the both sides of the scratch, which also has some certain antifraying characteristics.

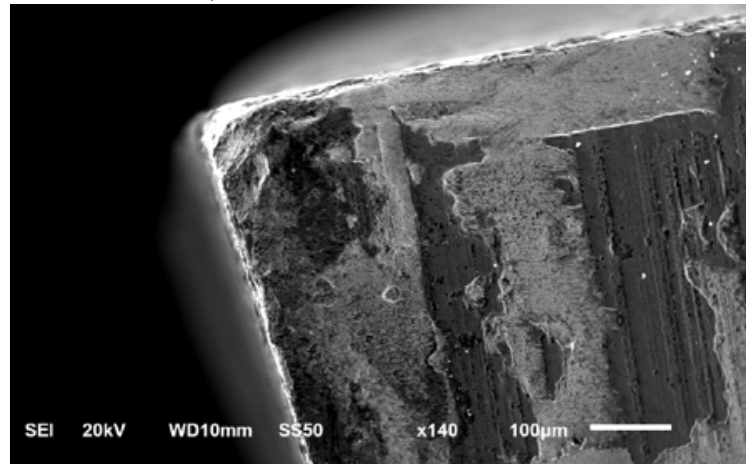

Fig.5 SEM micrograph of the worn rake face of the TiN coated carbide tool at the 32min.

Fig. 6 describes the EDS chemical composition analysis at flank face for new and worn cutting tools. The EDS analysis of components in a new insert shows high levels of the original coating elements (TiN). On the contrary, the analysis of worn inserts shows higher levels of iron, chromium. As mentioned in 2.1, these elements are alloying elements from the AISI 4119 steel. The mapping results indicate that TiN coating has been peeled off badly from the substrate. Then, parts of the tool rake face are not protected by the TiN layer. High content of tungsten and cobalt (from substrate) and low percentages of titanium, and nitrogen (from coating) are observed. This analysis indicates that tool coating has disintegrated by diffusion wear which occurs at high cutting temperatures.

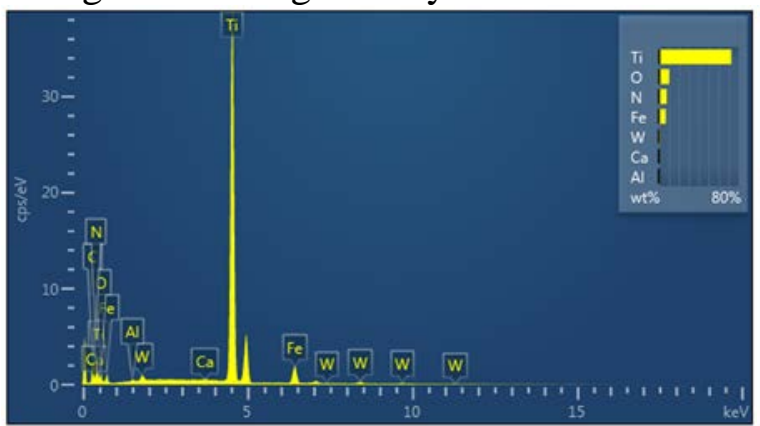

(a)

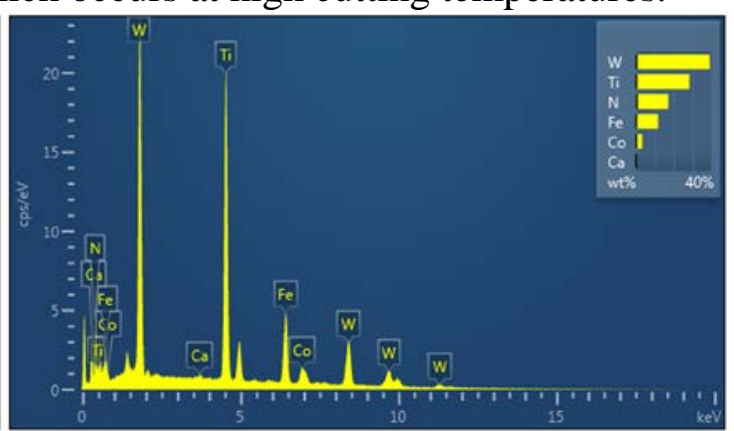

(b)

Fig.6 EDS chemical composition analysis at flank face for new (a) and worn (b) cutting tools. 


\section{Summary}

In this paper, the machinability and wear mechanism of TiN coated tools in dry turning of AISI 4119 steel are analyzed at various cutting speeds. From the foregoing, the following conclusions can be gotten:

(1) The TiN coatings show a lower friction coefficient and keep the longer friction stability time than substrate.

(2) Compared with uncoated tools, the surface quality and the cutting forces for the TiN coated inserts are noticed to be lower and showed a decreasing trend, especially as the cutting speed over 100 $\mathrm{m} / \mathrm{min}$.

(3) During machinability study in dry turning, under the various cutting conditions, the TiN coated carbide tools outperform the uncoated tool with regard to the wear resistance, providing lower wear width and wear value. The tool life for TiN coated carbide insert has been improved significantly.

\section{References}

[1]. Wenlong Song, Jianxin Deng, Hui Zhang, et al. Study on cutting forces and experiment of $\mathrm{MoS}_{2} / \mathrm{Zr}$-coated cemented carbide tool [J]. Int J Adv Manuf Technol. Vol. 49 (2010), p. 903-909.

[2]. Y. Sahin. Comparison of tool life between ceramic and cubic boronnitride (CBN) cutting tools when machining hardened steels [J]. Journal of Materials Processing Technology. Vol. 209 (2009) No. 7, p. 3478-3489.

[3]. H. C. Barshilia, K. Yogesh, K.S. Rajam. Deposition of TiAlN coatings using reactive bipolar-pulsed direct current unbalanced magnetron sputtering [J]. Vacuum. Vol. 83 (2009) No. 2, p. 427-434.

[4]. A. K. Sahoo, B. Sahoo. A comparative study on performance of multilayer coated and uncoated carbide inserts when turning AISI D2 steel under dry environment [J]. Measurement. Vol. 46 (2013) No. 8, p. 2695-2704.

[5]. M. C. Cakir, C. Ensarioglu, I. Demirayak. Mathematical modeling of surface roughness for evaluating the effects of cutting parameters and coating material [J]. J Mater Process Technol. Vol. 209 (2009) No. 1, p. 102-109.

[6]. A. I. Fernández-Abia, J. Barreiro, L. N. López de Lacalle, et al. Effect of very high cutting speeds on shearing, cutting forces and roughness in dry turning of austenitic stainless steels [J]. The International Journal of Advanced Manufacturing Technology. Vol. 57 (2011) No. 1-4, p. 61-71.

[7]. G. N. Virginia, G. Oscar, I. Bengoetxea. Effect of cutting parameters in the surface residual stresses generated by turninginAISI4340steel [J]. Vol. 61 (2012) No. 12, p.48-57.

[8]. N. Muammer, A. Abdullah G.Hasan. The effect of cutting speed and cutting tool geometry on machinability properties of nickel-base Inconel 718 super alloys [J]. Materials and Design. Vol. 28 (2007) No. 4, p. 1334-1338.

[9]. N. Zhong, Y. X. Zhou, X. F. Zhu, et al. Microstructure and cutting performance of carbonitride coated tools in high speed machining of 40Cr steel," Surface Engineering. Vol. 27 (2011) No. 4, p. 306-310.

[10]. S. M. Abhijeet, W. P. Jiang, W. D. Brown, et al. Tool wear and machining performance of cBN-TiN coated carbide inserts and PCBN compact inserts in turning AISI 4340 hardened steel [J]. Journal of Materials Processing Technology. Vol. 180 (2006) No. 1-3, p. 253-262. 